\title{
A herança de Ponciá Vicêncio
}

\author{
Ana Margarita Barandela \\ Professora da Faculdade de Letras da \\ Universidade Federal de Alagoas e doutoranda do \\ PPGLL-UFAL.
}

Resumo: Conceiçäo Evaristo, na sua obra Ponciá Vicêncio, traça a caminhada da protagonista Ponciá, desde sua infância, na zona rural, até a idade adulta na cidade grande, as perdas que acontecem na sua vida e a herança deixada pelo avô. Tendo como base os trabalhos de Bolivar (2005) e Prandi (1997; 2005) e auxiliada também por Eliade (2000) e Mielietinski (1973), observo a presença de mitos, deuses do panteāo yoruba, assim como os valores culturais relativos à religiāo dos afro-descendentes no Brasil. Também, observo a etimologia dos nomes Ponciá e Vicêncio e apresento uma outra interpretação para seu significado.

Palavras-chave: mitos; herança cultural; religiāo yoruba
Resumen: Conceiçāo Evaristo, en su obra Ponciá Vicêncio, traza la caminada de la protagonista Ponciá, desde su infancia, en la zona rural, hasta la edad adulta en la gran ciudad, las pérdidas por las que pasa en la vida y la herencia dejada por el abuelo. Utilizando como referencia los trabajos Bolivar (2005) y Prandi $(1997 ; 2005)$ y auxiliada también por Eliade (2000) y Mielietinski (1973), observo la presencia de mitos, dioses del panteón yoruba, así como los valores culturales relacionados con la religión en Brasil de los descendientes de africanos. También, observo la etimología de los nombres Ponciá y Vicêncio y presento otra interpretación para su significado.

Palabras claves: mitos; herencia cultural; religión yoruba 

A obra Ponciá Vicêncio, da escritora mineira Conceição Evaristo, narra a vida de uma mulher negra desde sua infância, no meio rural, até a idade adulta numa cidade para a qual a protagonista se traslada em busca de melhores condições de vida.

Nessa trajetória complexa, cheia de perdas e ganhos, a personagem Ponciá mistura seu passado e seu presente por meio das lembranças. Duarte (2006b) define Ponciá Vicêncio como um Bildungsroman feminino e negro, pela releitura que faz Evaristo do processo de crescimento linear dos romances clássicos de formação. Ponciá, no seu decorrer, não procura uma filosofia de vida nem uma vocação, não deverá realizar, como os personagens homens, um sem números de conquistas e processos de independência e autonomia, ou sua trajetória em direção a um grau determinado de perfeição. Ponciá procura uma identidade, uma realização e afirmação de seu EU em seus próprios termos. Essa busca da realização e integração da mulher é, segundo Pinto (1990), uma diferença básica entre o Bildungsroman tradicional - masculino-e o feminino.

Ponciá apresentaria características temáticas definidoras do que seria um Bildungsroman feminino e que seriam:

[...] infância da personagem, conflito de gerações, provincianismo ou limitação do meio de origem, o mundo exterior [...], auto-educação, alienação, problemas amorosos, busca de uma vocação e de uma filosofia de trabalho que podem levar a personagem a abandonar seu ambiente de origem e tentar uma vida independente. (PINTO 1990, p. 14)

No romance afro-brasileiro, o sujeito étnico se identifica com as marcas culturais da afro-ancestralidade, e acontece um encontro intercultural, no momento em que, mediante a criação artística do escritor, se põe em contato o africano com o europeu no território brasileiro. Em Ponciá Vicêncio essas marcas aparecem com a representação da 
crueldade da exclusão do sujeito afro-brasileiro nas relações sociais, especialmente nas relacionadas com o poder. Ponciá é um sujeito étnico, que tem as marcas da exclusão pela condição de ser mulher e negra num país onde o preconceito racial ainda está presente.

Em Ponciá Vicêncio, está presente a raiz africana como uma herança que não se abandona, uma herança que será conhecida na medida em que avança a narrativa, complexa e intermitente, na qual como aponta Duarte (2006a, p. 231): "se mescla de forma tensa passado e presente, recordação e devaneio" . Dessa raiz africana, é que proponho falar neste trabalho.

Já no segundo capítulo, o pai de Ponciá diz que Vô Vicêncio deixava uma herança para a menina (EVARISTO, 2006, p. 15), e durante a obra, o narrador voltará inúmeras vezes a repetir que existe uma herança que vai ser recebida, em seu devido momento, por ela.

Ponciá parece muito com seu avô fisicamente. Além da cor da pele e da fisionomia, caminha encurvada e com um dos braços escondido nas costas, como ele fazia, por causa de uma auto-mutilação num momento de desespero do escravo. O legado da neta é também cultural. É o conjunto dos padrões de comportamento, das crenças, e de outros valores morais e sociais, característicos de uma sociedade, neste caso, a africana.

A cultura os costumes e a religião do homem africano vieram junto com os escravos. "Nos flancos sonoros dos navios negreiros vieram não só os filhos da noite, mas também os seus deuses, os orixás dos bosques, dos rios e do céu africano" (BASTIDE, 2001, p. 327). O homem negro trouxe com ele, em sua viagem da África à América, determinados princípios e valores religiosos capazes de produzir e estruturar sua identidade e relações sociais. Como expõe Luz (2003), esses princípios regeram a sua vida, mesmo em condições históricas desfavoráveis, como foi a luta contra a escravidão.

Na obra Ponciá Vicêncio, essa cultura africana está simbolizada fundamentalmente por dois personagens: Vô Vicêncio e Nêngua Kainda, que 
representam os velhos guardiães da memória coletiva. Esses personagens não possuem nomes cristãos, o avô é simplesmente Vô, nunca saberemos seu nome. Por sua vez, Kainda é um nome africano e Nêngua significa sacerdotisa, que é verdadeiramente a função dessa mulher, encarregada da adivinhação do destino dos personagens da família de Ponciá.

Para valorizar a cultura oral africana e seus mediadores ${ }^{1}$, Evaristo representa esses personagens com um físico frágil, miúdo, delicado, que contrasta com a força e a liderança espiritual que exercem no interior de umı coletivo. Nos mediadores da memória oral, "há claramente uma contradição entre a fragilidade física e a força interior" (ROMARIZ, 1999, p. 188).

De Vô Vicêncio, o narrador diz: "era muito velho. Andava encurvadinho com o rosto quase no chão. Era miudinho como um graveto" (EVARISTO, 2006, p. 15). Também descreve a Nêngua Kainda como uma mulher muito velha, que parecia que congregava a velhice de todos os velhos do mundo (EVARISTO, 2006, p. 114), mas com um olhar vivo, enxergador de tudo (EVARISTO, 2006, p. 60):

A mulher sempre velha, muito velha como o tempo, parecia uma miragem. Só os olhos denunciavam a força não pronunciada de seu existir. O som de sua boca era quase inaudível, enquanto seu olhar penetrante vazava todo e qualquer corpo que se apresentava diante dela (EVARISTO, 2006, p. 93).

Vô, antigo escravo, carrega o sobrenome Vicêncio "reminiscência do poderio do senhor, de um tal coronel Vicêncio", dono daquelas terras. Ponciá nunca se identificaria com aquele sobrenome, que lembra a escravidão negra no Brasil, "continuava achando o nome vazio, distante". Ao escrevê-lo era "como se estivesse lançando sobre si mesma uma lâmina afiada a torturar-lhe o corpo" (EVARISTO, 2006, p. 29). Muitas vezes, ela mesma se chamava e não se reconhecia: "vazia se sentia sem nome. Sentia-se ninguém. Tinha, então, vontade de choros e risos"
${ }^{1}$ Segundo Romariz, os mediadores são "os homens velhos, guardiães da história coletiva" (1999, p.186). 
(EVARISTO, 2006, p. 19). Mas também não se reconhecia com outros nomes aparentemente de origem africana, como Panda, Malenga ou Quieti. Sua identidade, embora com raízes africanas, é uma identidade afro-brasileira na qual coexistem tanto a herança africana como a européia.

Se procuramos pela etimologia dio nome Vicêncio, descobrimos que deriva do latim Vincentiu, por sua vez, derivado do particípio vincens, que significa aquele que vence (MACHADO, 2003), enquanto que Ponciá, feminino de Poncio, de origem latina, deriva de Pontius que significa quinto e também que vem do mar.

Ponciá Vicêncio, embora não reconheça seu nome, "já que para ela era um nome que não tinha dono" (EVARISTO, 2006, p. 29), seria a quinta descendente de uma geração que vem do mar (antigos escravos que cruzaram o Oceano Atlântico) e que sempre vence porque guarda sua herança cultural e histórica; "Ponciá Vicêncio, elo e herança de uma memória reencontrada pelos seus, não se perderia jamais, se guardaria nas águas do rio" (EVARISTO, 2006, p. 128).

As raízes africanas estão representadas também pela recorrência ao barro, que relembra o mito da criação yoruba. O mito é uma narrativa fabulosa transmitida pela tradição, de conteúdo religioso, que procura explicar os principais acontecimentos naturais, históricos ou filosóficos sob forma imaginativa, em que a fantasia sugere e simboliza a verdade que se pretende transmitir.

O mito é uma realidade cultural extremamente complexa, que pode ser abordada e interpretada em perspectivas múltiplas e complementares [....] o mito conta uma história sagrada, relata um acontecimento que teve lugar no tempo primordial, o tempo fabuloso dos começos [...] o mito conta graças aos feitos dos seres sobrenaturais, uma realidade que passou a existir, quer seja uma realidade total, o Cosmos, quer apenas um fragmento, uma ilha, uma espécie vegetal, um comportamento humano, é sempre, portanto uma 
narração de uma criação; descreve-se como uma coisa foi produzida, como começou a existir (ELIADE, 2000, p. 12-13).

Ao valorizar o mito yoruba, em detrimento da ideia da concepção de base judaico-cristã ocidental, mais oficial e hegemônica, Evaristo propõe, no estrato literário, um novo olhar, uma re-escritura mítica que reivindique a posição marginalizada da mulher negra na sociedade brasileira.

$\mathrm{Na}$ mitologia yoruba o deus supremo Olorun, chamado também de Olodumare, criou o mundo, as águas e as terras, as plantas e os animais, e ordenou que Oxalá criasse o homem. Oxalá tentou criar o homem do ferro e da madeira, mas eram muito rígidos. Tentou de pedra, mas era muito frio. Experimentou a água, mas o homem não tomava forma definida. Ensaiou o fogo, mas a criatura se consumiu. Quis fazer o homem do ar, sempre sem êxito. Triste Oxalá sentou-se à beira do rio. Nana, ao saber do insucesso, mergulhou e lhe trouxe barro. Oxalá, então, cria o homem e percebe que ele é flexível, capaz de mover os braços, as pernas e, então, sopra-lhe a vida.

De forma semelhante como ocorre com Oxalá em relação ao homem, Ponciá e sua mãe criam potes, canecas, colheres, enfeites de barro. Essa re-visão do mito, em que a deidade masculina não é mais o criador, na qual esse papel recai sobre as figuras femininas, permite que se rompa a unidade das conceituações tradicionais e se promovam novas formas de entendimento do mundo, no qual as mulheres tornam-se visíveis. Assim, Ponciá se deixa ver pelos outros, e em particular se faz visível para o seu irmão Luandi que, no meio de uma exposição na cidade grande, consegue reconhecer as criações de barro da irmã, pela singularidade das mesmas:

Luandi olhava os trabalhos da mãe e da irmã como se os visse pela primeira vez, embora se reconhecesse em cada um deles. Observava as minúcias de tudo. Havia os objetos de uso: panelas, potes, bilhas, jarros 
e os de enfeites, em tamanho menor, pequeníssimos. Pessoas, animais, utensílios de casa, tudo coisas de faz-de-conta, objetos de enfeitar, de brincar. Criações feitas como se as duas quisessem miniaturizar a vida, para que ela coubesse e eternizasse'sobre o olhar de todos, em qualquer lugar (EVARISTO, 2006, p. 104-105).

Mas não é só a criação do homem, no universo de Ponciá, tudo é criado por igual, os homens, os animais e os objetos inanimados. É um mundo complexo e inteiramente novo que possibilita a sobrevivência da identidade histórica e cultural, e das raízes africanas da família Vicêncio, fora da comunidade à qual pertencem.

Segundo Mielietinski (1973), a narrativa latinoamericana do século XX resgata o sagrado e, nele, o mito como função artística ou como elemento do mundo. Em Ponciá Vicêncio, (embora uma obra do século XXI), o barro relembrando o mito da criação dos homens é um elo que está presente no decorrer da narrativa. A presença deste é fundamental desde a infância de Ponciá, e aparece nas lembranças da casa materna: "Fechou os olhos e relembrou da casinha de chão de barro batido de sua infância [...] Tudo ali era de barro. Panelas, canecas, enfeites e até uma colher com que a mãe servia o feijão" (EVARISTO, 2006, p. 25).

Nas imagens fantásticas da mitologia estão amplamente refletidos os traços reais do mundo circundante. Nesta representação da realidade pelo mito, existe até mesmo uma especial plenitude, porque todas as realidades sociais e naturais que tenham o mínimo de importância devem estar radicadas no mito (MIELIETINSKI, 1973, p. 198).

Também se faz referência, no processo da criação, à olaria, à diferença entre a maleabilidade do barro in natura e a sua força depois de queimado. Aquilo que podia ser moldado e trabalhado sairia fortalecido ao final da invenção e seria então resistente, sólido e forte, o que 
poderia ser preservado, da mesma forma que a identidade cultural de Ponciá. "A mãe fazia panelas, potes e bichinhos de barro. A menina buscava a argila nas margens do rio. Depois de seco, a mãe punha os trabalhos para assar num forno de barro também. As coisinhas saíam então duras, fortes, custosas de quebrar" (EVARISTO, 2006, p. 21). Ponciá se fortalece também, assim como o barro, com as adversidades, a morte do avô, do pai, a viagem para a cidade grande, espaço onde ela não encontra um lugar. A morte de todos os seus filhos, suas ausências, permite que ela se molde e se endureça como cerâmica que contém a verdadeira sustância identitária.

Mas a peça principal de toda a criação dela será a escultura do avô, escultura que representa o valor simbólico da cultura africana. Na memória individual de Ponciá pode ser reproduzida a força da herança deixada pelo avô e que está presente na batalha diária para escapar da marginalidade. A memória é "um elemento essencial do que se costuma chamar identidade, individual ou coletiva, cuja busca é uma das atividades fundamentais dos indivíduos e da sociedade de hoje, na febre e na angústia" (LE GOFF, 1996, p. 147). E na memória individual da personagem está contida a memória dos escravos africanos e seus descendentes, a cultura do afro-descendente.

Cada memória individual é um ponto de vista sobre a memória coletiva, que este ponto de vista muda conforme o lugar que ali eu ocupo, e que este lugar mesmo muda segundo as relações que mantenho com outros meios. [...] Todavia quando tentamos explicar essa diversidade, voltamos sempre a uma combinação de influências que são, todas, de natureza social. Dessas combinações, algumas são extremamente complexas. É por isso que não depende de nós fazê-las reaparecer. É preciso confiar no acaso. [...] A sucessão de lembranças [...] explicase sempre pelas mudanças que se produzem em nossas relações com os diversos meios coletivos (HALBWACHS, 1990, p. 77). 
Na memória individual de Ponciá, a imagem do avô, do qual não poderia lembrar, porque morreu sendo ela ainda criança de colo, representa essa memória coletiva de raízes africanas. O homem feito de barro, à imagem e semelhança do avô "era uma obra de Ponciá Vicêncio para ela mesma. Nada que pudesse ser dado ou vendido" (EVARISTO, 2006, p. 22). E essa representação no barro é o elo que une a infância e a maturidade de Ponciá, o ambiente rural e o urbano, o riso e o pranto, a felicidade e a infelicidade, o presente e as lembranças.

Aqui as recordações, as lembranças, de Ponciá resgatam o mito da criação yoruba e o tornam eterno. A representação do barro e da cerâmica permite reatar o fio da existência. Para Duarte (2006a), o barro deixa de ser um paliativo para a pobreza na infância de Ponciá e se converte em matéria-prima para confirmar seu desenvolvimento como mulher. Mas o barro em Ponciá é mais que um capítulo na história cultural da herança dos afrodescendentes, é um ato de sobrevivência da protagonista, o que permite identificar, na revisão do mito da criação yoruba, uma escrita de autoria feminina (RICH, 1979).

Não só porque os mitos fornecem uma explicação do mundo e da própria maneira de estar no mundo, mas sobretudo porque, ao recordar, ao reatualizálos, ele é capaz de repetir o que os Deuses, os Heróis ou os Antepassados fizeram ab origine. Conhecer os mitos é aprender o segredo da origem das coisas. Por outras palavras, aprende-se não só como as coisas passaram a existir, mas também onde as encontrar e como fazê-las ressurgir quando elas desaparecem (ELIADE, 2000, p. 19).

Um outro aspecto relacionado com esse mito da criação yoruba é a religião dos afrodescendentes.

A religião, de modo geral, reforça e mantém os valores culturais, estando muitos deles ligados à ética 
e à moral, pelo menos implicitamente. Sustenta e incute normas particulares de comportamento culturalmente aprovadas, exercendo, até certo ponto, poder coercitivo. Ajuda na conservação de conhecimentos ao transmitir, através de rituais e cerimônias dramatizadas, os procedimentos ou normas de conduta importantes em determinada cultura (MARCONI e PRESOTTO, 2001, p. 171).

Aparentemente a religião referenciada em Ponciá Vicêncioé a judaico-cristã, pois a menina Ponciá aprende a ler durante uma visita à região de missionários que, além de cumprir seus ofícios eclesiásticos, montaram uma escola e começaram a alfabetizar as crianças. Também o primeiro lugar que Ponciá visita, quando chega à cidade, é uma catedral, que a impressiona pelo luxo e esplendor, mas embora "a crença era o único bem que ela havia trazido para enfrentar uma viajem que durou três dias e três noites" (EVARISTO, 2006, p. 36), ela mal consegue terminar uma oração, pois ela não se identifica com aqueles deuses diferentes da sua realidade, da sua história.

Em contraposição à religião judaico-cristã, elementos referentes à religião de raízes africanas são encontrados na narrativa. Nas religiões de raízes africanas, a ênfase está na iniciação, que é quase interminável, gradual e secreta (PRANDI, 1997). Elas têm no Brasil nomes diferentes: candombl, na Bahia; xangô, em Pernambuco e Alagoas; tambor de mina, no Maranhão e Pará; batuque, no Rio Grande do Sul e macumba, no Rio de Janeiro (PRANDI, 1997).

O candomblé é uma religião iniciática, que se organiza a partir de um conceito de hierarquia. A ascensão hierárquica se faz pela relação tempo-conhecimento; a pessoa que conhece não sabe nem para si nem por si, sabe pelas necessidades e para um fim.

O saber é ao mesmo tempo o segredo, a necessidade e a capacidade de materializar o conhecimento, transmutando mitos em ritos, práticas e objetos. Quanto mais conhecimento tanto mais ritos, práticas e objetos (LEMOS, 2005). 
A viagem de Ponciá, Luandi e Maria à cidade representarja, assim, uma iniciação, um período de provação, de auto-confirmação e de resgate do conhecimento identitário. No candomblé, os filhos de santo precisam de um espaço de tempo para alcançar o conhecimento do fundamento da religião e dos orixás, e também como purificação, antes de fazer o santo.

O tempo na cidade simboliza esse período de privações, enquanto as lembranças da infância de Ponciá representariam a aquisição do conhecimento de si própria e da identidade à qual ela pertence. Essa viagem e esse tempo longe dos seus significariam a relação tempo-conhecimento necessária no período iniciático, indispensável para poder receber, no final da narrativa, a herança africana, o saber cultural, sua verdadeira identidade.

$\mathrm{Na}$ narrativa, os deuses do panteão yoruba se fazem presentes. O primeiro deles é Oxumaré, o orixá do arco-íris. É considerado uma grande serpente que, ao aparecer no céu, representa uma benção para a humanidade. É andrógino e simboliza tanto a mobilidade quanto a permanência (BOLIVAR, 2005), e o mito diz que durante seis meses é um monstro e durante os outros seis meses, uma linda mulher (PRANDI, 2005, p. 227), por isso a lenda conta que quem passar por baixo do arco-íris também mudará de sexo, como pensa Ponciá nesse fragmento:

Quando Ponciá Vicêncio viu o arco-íris no céu, sentiu um calafrio. Recordou o medo que tivera durante toda a sua infância. Diziam que menina que passasse por debaixo do arco-íris virava menino. Ela ia buscar o barro na beira do rio e lá estava a cobra celeste bebendo água. Como passar para o outro lado? Às vezes, ficava horas e horas na beira do rio esperando a colorida cobra do ar desaparecer. Qual nada! O arco-íris era teimoso! Dava uma aflição danada. Sabia que a mãe estava esperando por ela. Juntava, então, as saias entre as pernas tampando o 
sexo e, num pulo, com o coração aos saltos, passava por debaixo do angorô. Depois se apalpava toda. Lá estavam os seinhos, que começavam a crescer. Lá estava o púbis, bem plano, sem nenhuma saliência a não ser os pêlos. Ponciá sentia um alívio imenso. Continuava menina. Passara rápido, de um só pulo. Conseguira enganar o arco e não virara menino (EVARISTO, 2006, p. 13).

Oxumaré está representado também por um ouroboro, a serpente que morde a própria cauda. Este símbolo contém as ideias de movimento, continuidade e, em consequência, o perpétuo retorno. Condenada a serpente a jamais escapar de seu ciclo, eleva-se a cada volta a um nível superior, a um círculo indefinido de renascença. Assim também Ponciá retornará com uma nova herança para o lugar do qual tinha partido, "Voltava para o rio, para as águas-mãe” (EVARISTO, 2006, p. 124).

Um outro orixá que podemos encontrar em Ponciá Vicêncio será Euá. Este orixá mora dentro dos cemitérios entre as tumbas e os mortos; seus servidores são mulheres estéreis (BOLIVAR, p. 249). Segundo Prandi (2005, p. 236), é a esposa ou a irmã de Oxumaré e foi expulsa de casa por ter tido um filho que perdeu na floresta. Manuel Cofiño a descreve poeticamente com as seguintes palavras:

Es la pastora con su capa de viento, al lado de la muerte. Solemne. Perfecta de modestia sin sombra. Tiene una boca triste, $\mathrm{y}$ unas sienes tristes, y unos dedos más tristes todavía. Diosa de angustia. Yewá, santa fatal de soledades. Enferma, de silencio vive en el cementerio, esa gran república de huesos, donde la tierra es honda y no hay raíces. El aire la traspasa, y ella quiere cantar, pero no puede. Rechaza los tambores y los sexos. Entiende lo que dice el viento. Palpita entre las tumbas y los pinos. Pastorea recuerdos entre hierbas y cruces (COFIÑO, 1979, p. 94). 
Euá nos lembra Ponciá no período que morou na cidade, sozinha, aflita, sem filhos, porque morrem ou nascem mortos, sempre ausente, imersa nas lembranças, fraca para viver, mas sem coragem para morrer. Associamos Ponciá, na sua passagem pela cidade, com o conceito de não-lugar (AUGÉ, 1994), em que ela ocupa um espaço oposto ao espaço investido de sentido, um espaço que não pode se definir como identitário, relacional e histórico. É um espaço com caráter transitório e que serve para gerar solidão.

E agora, ali deitada de olhos arregalados, penetrados no nada, perguntava-se se valera a pena ter deixado a sua terra. $O$ que acontecera com os sonhos tão certos de uma vida melhor? Não eram somente sonhos, eram certezas! Certezas que haviam sido esvaziadas no momento em que perdera o contato com os seus. E agora feito morta-viva, vivia. (EVARISTO, 2006, p. 34)

Por isso Ponciá precisa retornar a sua terra, na área rural e construir um lugar no qual possa encontrar sua identidade: "Ponciá voltaria ao lugar das águas e lá encontraria a substância, o húmus para o seu viver" (EVARISTO, 2005, p. 125).

Obaluaiyêtambém se faz presente nas feridas das mãos de Ponciá. Este é o orixá da lepra, da varíola, das enfermidades venéreas e das afecções da pele, veste palha e esconde o segredo da vida e da morte (BOLIVAR, 2005, p. 257). Pode trazer a doença, mas também a leva embora. Ligado à morte, suas faculdades destruidoras são de difícil controle; é o dono da terra, é antropófago, come a carne e destrói os ossos.

Quando Ponciá volta pela segunda vez à cidade ainda sozinha, sem seus seres queridos, a cidade já não tem sentido, pois ela está solitária, acreditando que perdeu o elo com os vivos e com os mortos; quando deixa de criar coisas com argila, suas mãos ficam doentes e com cheiro do barro: 
Na primeira manhã em que Ponciá Vicêncio amanheceu novamente no emprego depois do retorno à terra natal, levantou-se com uma coceira insistente entre os dedos da mão. Coçou tanto até sangrar $[\ldots]$ a toda hora interrompia o trabalho e levava as mãos debaixo d'água para ver se aliviava o incômodo [...] cheirou a mão e sentiu o cheiro do barro (EVARISTO, 2006, p. 74).

Esse mesmo odor de barro que sente nas feridas da pele emana da escultura de seu avô e descobre, assim, que sente saudades do barro e da criação. Essa facilidade de criar objetos com o barro parece ser, para Ponciá, como uma missão a ser cumprida. Suas obras eram reconhecidas pela mãe, que "tinha a impressão de que a filha não trabalhava sozinha, algum dom misterioso guiava as mãos da menina" (EVARISTO, 2006, p. 84).

Outro elemento relacionado com as religiões de raízes africanas é o que se refere à ideia da convivência dos homens vivos com os mortos e com os que estão por nascer. Para as culturas yorubase fon, conhecidas no Brasil como jeje-nagô, a vida não termina com a morte, existindo um processo divino de existência única. Olodumare, o criador, oferece aos homens um conjunto de forças sagradas que possibilita a vida. Esses aspectos não morrem nas cerimônias de axexé(cerimônias fúnebres), pois voltam a suas origens, ao orum. Essas forças que animaram os antepassados voltam para animar os descendentes e discípulos. A ancestralidade confirma a imortalidade, pois a vida continua no orum. Por isso, a presença dos que já partiram permanece fazendo parte da vida. Essa presença pode estar na estatua de Vô Vicêncio, nas canecas intocadas dos membros da família, ou no espaço do pai Vicêncio, como vemos a continuação:

A mãe "sempre conservou as coisas do homem no mesmo lugar. E nos dias em que o filho regressava do trabalho, ela esperava por ele na soleira da porta e depois que o abençoava, caminhava para frente 
cinco passos e com um gesto longo e firme abraçava o vazio. A mulher não acreditava que seu homem tivesse apartado de vez" (EVARISTO, 2006, p. 32).

Também no candomblé não existe a noção de pecado, tal como se entende na religião judaico-cristã. Ćada pessoa é como seu orixá, tem virtudes e defeitos, e, para conseguir o equilíbrio, é preciso efetuar os sacrifícios e as oferendas. O candomblé não prega o medo, a punição, o certo contra o errado, nem o bem contra mau; o candomblé cultua a natureza em estado puro, as forças em estado puro, não há pecadores. Por isso Luandi ama Bilisa, embora ela seja "mulher-dama". Bilisa é uma prostituta pelas condições sociais de desigualdade e preconceito. Ainda trabalhando de doméstica, foi explorada sexualmente e roubada. Mas ela também pode ser filha de Oxum, orixá símbolo da sexualidade feminina e, assim como a deusa, não entende a relação com vários homens como um pecado, e sim como um prazer natural. Oxum, como deusa símbolo da vaidade e da graça feminina, pode resolver ou provocar brigas entre os orixás e os homens pelo desejo de possuíla. Cofiño a descreve poeticamente:

Antes se hartará el fuego de la madera y el mar del agua que Oshún de los hombres. El placer vive en sus pechos. Tiene nombre de río. Diosa y Santa de Corona es, ante todo, hembra, más terrenal que divina. [...] Siente el jadeo de los dioses que la siguen. Los labios de los santos quieren besarle los muslos, los dientes de los reyes quieren morderle las caderas. [...] Todo lo puede. No es de nadie y es de todos. [...] bailando con los cinco pañuelos que le cuelgan de la cintura, sus íntimos cendales, moviendo sus cinco manillas de oro. Y se acuesta con ellos, húmeda, entre naranjas, adornada con plumas de pavo real, embarrada en miel y olorosa a canela (COFIÑO, 1979, p. 65). 
Da mesma forma que a deusa que desfruta do desejo carnal com naturalidade, sem nenhum tipo de pudor, Bilisa também sem preconceitos se entrega ao sexo, buscando a felicidade, o gozo. Esta personagem não é influenciada nem pela falsa moral burguesa, nem pela noção de pecado; ela se deixa levar livremente pelo próprio desejo, estabelecendo uma relação de equivalência para com sua orixá, sobre a base das similaridades de comportamento entre uma e outra. Oxum, assim como suas filhas, é considerada um resumo do ideal feminino: sensual, ingênua, dócil e infantil, desejosa de curar, ajudar e cuidar dos fracos. Por isso, carinho e gratidão são os sentimentos que Oxum desperta.

A prostituição, considerada uma degradação moral pela sociedade patriarcal, é ao mesmo tempo materializada no domínio dos homens sobre as mulheres, que têm seus corpos considerados objetos para atender as necessidades sexuais dos homens. Tal prática é contestada pela personagem Bilisa com a representação do seu corpo sexuado "sem pecado", seu comportamento fora dos padrões sociais normativos e sua rebeldia contra os limites impostos pelo sistema cultural, social e econômico sobre o que pode ou não ser feito do corpo. Nesse momento, Bilisa apresenta um o "corpo erotizado" (XAVIER, 2006, p. 228) e usufrui desse prazer como forma de emancipação.

Moça Bilisa se sabia ardente, deitara algumas vezes com os companheiros de roça, e alguns saiam mais e mais desejosos dos encontros com ela. Um dia, um homem enciumado chamou Bilisa de puta. A moça nem ligou. Puta é gostar do prazer. Eu sou. Puta é esconder no mato com quem eu quero? Eu sou. Puta é não abrir as pernas para quem eu não quero? Eu sou (EVARISTO, 2006, p. 98-99).

Bilisa, cheia de vida, prazer e otimismo, contrasta com a personagem Ponciá, que vegeta na cidade grande, não sente prazer no sexo e sente a morte de seus sete 
filhos. Mas ambas representam, na narrativa feminina da Evaristo, a luta contra o preconceito de raça e gênero, a marginalidade e a crueldade do cotidiano dos excluídos.

Segundo Duarte (2006b) e Barbosa (2006), a personagem Ponciá Vicêncio sofre, desde sua infância até sua vida adulta, inúmeras perdas até chegar a se afastar, a sumir de si mesma, culminando numa grande ausência. Entre essas perdas, estaria a do próprio nome Vicêncio que, proveniente de um antigo dono de escravos, denunciaria a herança da escravidão negra no Brasil.

Analisando a etimologia dos nomes Ponciá e Vicêncio, restabeleço uma relação identitária da protagonista com o nome e o sobrenome, pois será precisamente Ponciá a vencedora que, descendente de uma geração de escravos, consegue resgatar sua herança cultural de raízes africanas. Herança expressa no romance, não só pela discriminação social e racial dos escravos e seus descendentes, mas também por elementos culturais de origem africana que são corroborados no decorrer da narrativa. Entre esses elementos, são de grande significação a recorrência ao mito da criação yoruba, às referências ao panteão das deidades africanas, além das diferenças que apresenta a religião yoruba em relação à religião judaico-cristã ocidental, no relacionado, principalmente, com a noção de pecado e com a convivência dos vivos e os mortos.

Em Ponciá Vicêncio, o que parece ser um percurso de perdas materiais, familiares e culturais (DUARTE, 2006a) se contrapõe a uma etapa de auto-conhecimento, um aprofundamento no universo dos personagens, o que se estrutura como um período iniciático, através do qual a personagem Ponciá consegue receber sua herança cultural.

Concordo que Ponciá, em seu estado miserável, de marginalidade, injustiças e desigualdades sociais, representa grande parte das mulheres negras no Brasil que, na luta pela sobrevivência, resgatam e reinventam a própria identidade, mas, na minha opinião, Conceição Evaristo, neste romance, além de falar de classe e de raça, cria, em 
sua obra, um espaço em que fala principalmente de raízes culturais oriundas da África e trazidas para o Brasil junto com o triste episódio que foi a escravidão.

\section{Agradecimentos}

Quero agradecer os comentários à versão inicial deste artigo realizados pelas professoras Dra. Ildney Cavalcanti, Dra. Izabel Brandão e dois pareceristas anônimos. 
AUGÉ, Marc. Não-lugares. Introdução a uma antropologia da supermodernidade. São Paulo: Papirus, 1994.

BARBOSA, Maria José S. Prefácio In: EVARISTO, Conceição. Ponciá Vicêncio. Edição Especial. Belo Horizonte: Maza, 2006.

BASTIDE, Roger. O Candomblé da Bahia. São Paulo:

Companhia das Letras, 2001.

BOLÍVAR, Natalia. Los Orishas en Cuba. Ciudad de Panamá: Mercie Ediciones, 2005.

COFIÑO, Manuel. Cuando la sangre se parece al fuego. 3 ed., La Habana: Editorial Letras Cubanas, 1979.

DUARTE, Eduardo de Assis. Memória e ficção na narrativa feminina afro-brasileira. In: MONTEIRO, Maria Conceição; LIMA, Tereza Marques de Oliveira (Orgs.). Entre o estético e o político: a mulher nas literaturas clássicas e vernáculas.

Florianópolis: Ed. Mulheres, 2006a, p. 227-232.

. O Bildungsroman afro-brasileiro de Conceição

Evaristo. Revista Estudos Feministas, Florianópolis, v. 14, n. 1, 2006b. Disponível em: <http://www.scielo.br/

scielo.php?script=s ci_arttext\&pid=S0104-26X2006000100017 \&lng=en\&nrm=iso >. Acesso em: 24 Jan 2008.

ELIADE, Mircea. Aspectos do mito. Lisboa: Edições70, 2000.

EVARISTO, Conceição. Ponciá Vicêncio. Edição Especial. Belo Horizonte: Maza, 2006.

HALBWACHS, Maurice. A memória coletiva. São Paulo: Vértice, 1990.

LE GOFF, Jacques. História e memória. São Paulo: Editora Unicamp, 1996. 
LEMOS, Guilherme Augusto Rezende. Fios de Tempo.

Hispanista, n. 22, julio-agosto-septiembre, 2005. Disponível em: <http://www.hispanista.com.br/revista/artigo187esp.htm> Acesso em: 13 out. 2005.

LUZ, Marco Aurélio. Agadá: Dinâmica da civilização africanobrasileira. Salvador: EDUFBA, 2003.

MACHADO, José Pedro. Dicionário onomástico etimológico da Língua Portuguesa. 3 ed., Lisboa: Livros Horizontes, 2003.

MARCONI, Marina de Andrade; PRESOTTO, Zélia Maria Neves, Antropologia: uma introdução. 5.ed. São Paulo: Atlas, 2001.

MIELIETINSKI, Eleazar M. A poética do mito. Rio de Janeiro: Forense-Universitária, 1973.

PINTO, Cristina Ferreira. O Bildungsroman feminino: quatro exemplos brasileiros. São Paulo: Perspectiva, 1990.

PRANDI, Reginaldo. Mitologia dos orixás. São Paulo: Companhia das Letras, 2005. . Herdeiras do axé São Paulo: Hucitec, 1997.

$\mathrm{RICH}$, Adriene. When we dead awaken: writing as re-vision In: . On lies, secrets, and silnce. Selected Prose 1966-1978.

New York-London: W.W. Norton Company, 1979.

ROMARIZ, Vera. Palavra de deuses, memória de homens: diálogo de cultura na ficção de Adonias Filho. Maceió: EDUFAL, 1999.

XAVIER, Elódia. Que corpo é esse? In: CAVALCANTI, Ildney; ACIOLI LIMA, Ana Cecília; SCHNEIDER, Liane (Orgs.) Da mulher às mulheres: dialogando sobre literatura gênero e identidades. Maceió: EDUFAL, 2006. 